\title{
Study of Mechanical Behavior of Friction Welded Joint in a Brass Material and Its Statistical Modelling
}

\author{
Sirajuddin Elyas. Khany ${ }^{1}$ G.M. Sayeed Ahmeed ${ }^{2}$ Aleem Pasha $^{3}$ \\ ${ }^{1,2}$ Associate Professor, Department of Mechanical Engg. M.J.College of Engineering \&Technology, Hyderabad \\ AP-500034. \\ 3. Assistant Professor, Department of Mechanical Engg. Nalgonda Institute of Technology \& Science, Nalgonda
} District.

\begin{abstract}
Friction welding is used in many fields because the procedure is easily automated and it is possible to weld similar and dissimilar materials. It can be used to weld the materials which can not be welded by resistance welding due to electrical and heat conductivity. It can also be applied to weld the materials which have the low co-efficient of friction such as BRASS.Brass is an alloy of $57 \% \mathrm{cu}$ and $40 \% \mathrm{Zn}$ and $3 \% \mathrm{~Pb}$ its characteristics are high tensile strength, high resistance to corrosion, easily machinable and low co-efficient of friction. In this research the brass was selected because it can not be weld by resistance welding and arc welding due to high conductivity and it can not be welded by friction welding at normal working parameters due to low co-efficient of friction, but by controlling the parameters it is possible to weld with equally good tensile strength and other mechanical properties. Hence this research mainly concentrates on, The suitable friction welding parameters for the brass material by friction welding to attain the required tensile strength.
\end{abstract}

Key Words: - Friction welding, Tensile strength, upset, microstructures, Minitab software, DOE, TAGUCHI, REGESSION, ANOVA.

\subsection{Taguchi design:-}

\section{Statistical Modelling}

A Taguchi Design or an orthogonal array is a method of designing experiments that usually requires only a fraction of the full factorial combinations. An orthogonal array means the design is balanced so that factor levels are weighted equally. Because of this, each factor can be evaluated independently of all the other factors, so the effect of one factor does not influence the estimation of another factor.In robust parameter design, you first choose control factors and their levels and choose an orthogonal array appropriate for these control factors. The control factors comprise the inner array. At the same time, you determine a set of noise factors, along with an experimental design for this set of factors. The noise factors comprise the outer array.The experiment is carried out by running the complete set of noise factor settings at each combination of control factor settings (at each run). The response data from each run of the noise factors in the outer array are usually aligned in a row, next to the factors settings for that run of the control factors in the inner array. For an example, see data for analysis using Taguchi design L9 $(3 * * 4)$

\section{L9 (3**4) REPRESENTS:-}

- L9 9 RUNS

- 3 LEVELS

- 4 4FACTORS

The following are the 3 Levels which are considered in Taguchi design

- High 3

- Medium 2

- Low 1

\subsection{Experimentation}

Preparation of specimen:

This project involves the experimental study on friction welding of similar material of brass. For all the friction welding system, rotational speed, friction pressure, forge pressure applied to the parts and friction time are the principle controlling variables which influence the metallurgical and mechanical properties of friction welded joints. These similar joints thus prepared with friction welding techniques have been studied for tensile strength and up set values. 
BASE MATERIAL CHEMICAL COMPOSITION:-

Table 1.1: Base material chemical composition

\begin{tabular}{|c|c|c|c|}
\hline Element & $\mathbf{C u}$ & $\mathbf{Z n}$ & Lead \\
\hline Percentage (\%) & $\mathbf{7 0}$ & $\mathbf{2 8}$ & $\mathbf{2}$ \\
\hline
\end{tabular}

1.3 Specifications of work piece:-

- Diameter of Rod

$20 \mathrm{~mm}$

- Length of Rod $200 \mathrm{~mm}$

- Total length

- Total rods/each weld $400 \mathrm{~mm}$

- Total welds

2

- Total rods $9 \times 2=8$

1.4 Factors considered for Taguchi design of matrix:-

- Speed

- Friction time

- Friction pressure

- Forging pressure

1.5 Response variables:-

- Tensile strength

- Up-set

1.6 Friction-welding factors used For 3 Levels:-

Table 1.2: Friction welding factors for 3 levels

\begin{tabular}{|l|l|l|l|}
\hline \multicolumn{1}{|c|}{ Factors } & High & Medium & Low \\
\hline Speed (R.P.M) & 1600 & 1500 & 1400 \\
\hline Friction Pressure (Bar) & 20 & 15 & 10 \\
\hline Friction Time (Sec) & 6 & 5 & 4 \\
\hline Forging Pressure (Bar) & 30 & 25 & 20 \\
\hline
\end{tabular}

1.7 Constant Factors in Experiment:-

- Forging Time $(\mathrm{Sec}) \quad 3$

- Brake Delay (Sec) 0.1

- Upset Delay (Sec) 0.3

- Feed (\%) 75

1.8 Factors for DOE:-

- Speed C1

- Friction Time C2

- Friction pressure $\mathrm{C} 3$

- Forging pressure $\mathrm{C} 4$

2.1 Taguchi Design:

II. Design Of Experiment:-

Taguchi Orthogonal Array Design L9 (3**4)

NO of Factors: 4

NO of Runs: $\quad 9$

NO of Levels: 3

Columns of L9 $(3 * * 4)$

2.2 Taguchi Orthogonal Array Design L9 $(3 * 4)$ considered for conucting the experiment and the data is analysed.

\section{Results and Discussion}

3.1 Tensile strength and Upset of Brass:-

Tensile strength and Upset of Brass were calculated for various levels of rotational speed, friction time, friction pressure and forging pressure. Forging time, Upset delay and Brake delay was maintained constant. 
Study Of Mechanical Behavior Of Friction Welded Joint In A Brass Material And Its Statistical INPUT Variables for 9Runs, 3Lvels and 4 Factors:-

Table 3.1: Input variables for 9Runs, 3Lvels and 4 Factors

\begin{tabular}{|c|c|c|c|c|}
\hline Runs & Speed(R.P.M) & $\begin{array}{c}\text { Friction Pressure } \\
\text { (bar) }\end{array}$ & Friction Time (Sec) & Forging pressure \\
\hline $\mathbf{1}$ & 1400 & 10 & 4 & 20 \\
\hline $\mathbf{2}$ & 1400 & 15 & 5 & 25 \\
\hline $\mathbf{3}$ & 1400 & 20 & 6 & 30 \\
\hline $\mathbf{4}$ & 1500 & 10 & 5 & 30 \\
\hline $\mathbf{5}$ & 1500 & 15 & 6 & 20 \\
\hline $\mathbf{6}$ & 1500 & 20 & 4 & 25 \\
\hline $\mathbf{7}$ & 1600 & 10 & 6 & 25 \\
\hline $\mathbf{8}$ & 1600 & 15 & 4 & 20 \\
\hline $\mathbf{9}$ & 1600 & 20 & 5 & \\
\hline
\end{tabular}

The Above Table Represents or Explains about the Input variables which were considered for calculating the tensile strength for three levels which are High, medium and low. These 4 factors entered into the table according to Taguchi design matrix which is shown in table 5.1.

3.2 Constant Factors which were considered in Friction welding are as under:-

Table 3.2: Constant Factors which were considered in Friction welding

\begin{tabular}{|c|c|c|c|c|}
\hline Constant Factors & $\begin{array}{c}\text { Forging time } \\
\text { (sec) }\end{array}$ & Brake Delay (sec) & Upset Delay (sec) & $\begin{array}{c}\text { Feed } \\
\%\end{array}$ \\
\hline 1 to 9 Runs & 3 & 0.1 & 0.3 & 75 \\
\hline
\end{tabular}

The Above Table 5.3 Shows the constant values which were considered for 4 factors for all 9 runs.

\subsection{Ultimate Tensile Strength Test results:-}

Table 3.3: Ultimate Tensile Strength Test results

\begin{tabular}{|c|c|c|c|}
\hline RUNS & $\begin{array}{c}\text { Breaking or MAX. } \\
\text { Load (N) }\end{array}$ & $\begin{array}{c}\text { Ultimate Tensile } \\
\text { Strength }\left(\mathbf{N} / \mathbf{m m}^{\mathbf{2}}\right)\end{array}$ & Fractured At \\
\hline 1 & 49200 & 314.97 & WELD \\
\hline 2 & 54000 & 343.75 & WELD \\
\hline $\mathbf{3}$ & $\mathbf{5 3 6 0 0}$ & $\mathbf{3 4 7 . 5 6}$ & NECK \\
\hline $\mathbf{4}$ & $\mathbf{5 5 6 0 0}$ & $\mathbf{3 6 3 . 1 2}$ & NECK \\
\hline 5 & 52400 & 345.68 & WELD \\
\hline 6 & 44400 & 295.88 & WELD \\
\hline 7 & 52400 & 346.67 & WELD \\
\hline 8 & 56000 & 354.97 & WELD \\
\hline 9 & 50800 & 344.48 & \\
\hline
\end{tabular}

The Table 3.3 Which Shows the Ultimate Tensile Strength, Breaking Loads and Where the Fractured takes place. In that above Results Only 7 samples were fractured at the weld portion i.e. $(1,2,5,6,7,8$, and 9) and 2 samples were fractured at the Neck portion i.e. $(3,4)$

For the samples 3 and 4 which were fractured at Neck portion have the more Ultimate Tensile Strength than the base material, because they failed at neck portion. The friction welded joint has the more tensile strength than the base material. In that 2 samples which were failed at neck one sample has more ultimate tensile strength than the other sample. The sample 4 has more tensile strength $\left(363.12 \mathrm{~N} / \mathrm{mm}^{2}\right)$ and it with stand more load $(55600 \mathrm{~N})$, which was welded at rotational speed of 1500 R.P.M , friction time 5 sec, friction pressure 10 bar forging pressure 30 bar.

3.4 Input variables and Test results of RUN4 or Specimen 4:-

Table3.4: Input variables and Test results of RUN4 or Specimen 4

\begin{tabular}{|c|c|c|c|c|c|c|c|}
\hline Run & $\begin{array}{c}\text { Speed } \\
\text { R.PM }\end{array}$ & $\begin{array}{c}\text { Friction } \\
\text { time(sec) }\end{array}$ & $\begin{array}{c}\text { Friction } \\
\text { pressure(bar) }\end{array}$ & $\begin{array}{c}\text { Forging } \\
\text { pressure(bar) }\end{array}$ & $\begin{array}{c}\text { Maximum } \\
\text { Load(N) }\end{array}$ & $\begin{array}{c}\text { Tensile } \\
\text { Strength } \\
\left(\mathbf{N} / \mathbf{m m}^{\mathbf{2}}\right)\end{array}$ & $\begin{array}{c}\text { Fracture } \\
\text { At }\end{array}$ \\
\hline 4 & 1500 & 5 & 10 & 30 & 55600 & 363.12 & NECK \\
\hline & & & & & & & \\
\hline
\end{tabular}


After observation input variables of specimen 4 which gets more tensile strength, the Rotational speed and Forging pressure are has more importance in the friction welding because in this specimen Rotational speed is 1500 R.P.M and forging pressure is 30 bar which were considered for medium and high level respectively in the Taguchi Design matrix. Friction time has the medium effect on the friction welding. In this specimen friction time was $5 \mathrm{sec}$ which was considered for medium level in the Taguchi design. Friction pressure has low effect on the friction welding. In this specimen friction pressure was 10 bars which were considered for low level in the Taguchi design.

3.5 Optimum input variables of friction welded joint for Optimum Tensile strength: (BRASS).

- Rotational speed

- Friction Time

1500 R.P.M

- Friction Pressure $5 \mathrm{Sec}$

- Forging Pressure 20 bar

3.6 UPSET Test results:-

Table 3.5: shows the Upset results for 9 Runs, 4 factors and 3 levels.

\begin{tabular}{|c|c|c|c|c|c|}
\hline Runs & $\begin{array}{c}\text { Length(L1) } \\
\mathbf{m m}\end{array}$ & $\begin{array}{c}\text { Length(L2) } \\
\mathbf{m m}\end{array}$ & $\begin{array}{c}\text { Total length (L) } \\
\text { (before welding) } \\
(\mathbf{L 1}+\mathbf{L} \mathbf{2}) \mathbf{~ m m}\end{array}$ & $\begin{array}{c}\text { Final length }\left(\mathbf{L}_{\mathbf{R}}\right) \\
\text { (after welding) } \mathbf{m m}\end{array}$ & $\begin{array}{c}\text { UP SET } \\
(\mathbf{L o s s} \text { in } \\
\text { length) }\left(\mathbf{L}-\mathbf{L}_{\mathbf{R}}\right) \\
\mathbf{m m}\end{array}$ \\
\hline $\mathbf{1}$ & $\mathbf{1 0 0}$ & $\mathbf{1 0 0}$ & $\mathbf{2 0 0}$ & $\mathbf{1 9 4}$ & $\mathbf{6}$ \\
\hline 2 & 100 & 100 & 200 & 187 & 13 \\
\hline 3 & 100 & 100 & 200 & 180 & 20 \\
\hline 4 & 100 & 100 & 200 & 187 & 13 \\
\hline 5 & 100 & 100 & 200 & 187 & 13 \\
\hline 6 & 100 & 100 & 200 & 186 & 14 \\
\hline 7 & 100 & 100 & 200 & 183 & 17 \\
\hline 8 & 100 & 100 & 200 & 185 & 15 \\
\hline 9 & 100 & 100 & 200 & 183 & 17 \\
\hline
\end{tabular}

The above results given that how much length was reduced after friction welding process. Upset means how much length reduced after welding process, In 9 Runs or 9 specimens Loss in length was very small for specimen 1 which was welded at rotational speed, friction time, friction pressure and forging pressure were 1400 R.P.M, 4 Sec, 10 bar and 20 bar respectively. Optimum Upset obtained at low level factors which were considered for low level in Taguchi design. It means that the speed, friction time, friction pressure and forging pressure have the uniform effect on the upset. If rotational speed, friction time, forging pressure and friction pressure decreases Upset also decreases effectively.

3.7 Optimum input variables of friction welded joint for Minimum UPSET: (BRASS)

- Rotational speed 1400 R.P.M

- Friction Time 4 Sec

- Friction Pressure 10 bar

- Forging Pressure 20 bar

3.8 Summary of Experimental Results of Tensile and Upset for 9 Runs:

Table 3.6: Summary of Experimental Results of Tensile and Upset for 9 Runs

\begin{tabular}{|c|c|c|c|c|c|c|c|c|c|c|c|c|c|c|c|c|}
\hline $\begin{array}{l}\text { S. } \\
\mathbf{N} \\
\mathbf{O}\end{array}$ & $\begin{array}{l}\mathbf{L 1} \\
\mathbf{m} \\
\mathbf{m}\end{array}$ & $\begin{array}{l}\mathbf{L 2} \\
\text { m } \\
\text { m }\end{array}$ & $\begin{array}{c}\text { L- } \\
\text { Tot } \\
\text { al } \\
\text { m } \\
\text { m }\end{array}$ & $\begin{array}{c}\text { Fina } \\
\text { l } \\
\text { lengt } \\
\text { h } \\
\mathbf{m m}\end{array}$ & $\begin{array}{l}\text { Up } \\
\text { set } \\
\text { m } \\
\text { m }\end{array}$ & $\begin{array}{l}\text { Fric } \\
\text { tion } \\
\text { tim } \\
\text { e } \\
\text { sec }\end{array}$ & $\begin{array}{l}\text { Fric } \\
\text { tion } \\
\text { pres } \\
\text { sure } \\
\text { bar }\end{array}$ & $\begin{array}{c}\text { For } \\
\text { gin } \\
\text { g } \\
\text { pre } \\
\text { ssu } \\
\text { re } \\
\text { bar }\end{array}$ & $\begin{array}{c}\text { R.P. } \\
\text { M }\end{array}$ & $\begin{array}{l}\text { For } \\
\text { ging } \\
\text { time } \\
\text { sec }\end{array}$ & $\begin{array}{l}\text { Bra } \\
\text { ke } \\
\text { del } \\
\text { ay } \\
\text { sec }\end{array}$ & $\begin{array}{l}\text { Up } \\
\text { set } \\
\text { del } \\
\text { ay } \\
\text { sec }\end{array}$ & $\begin{array}{l}\mathbf{F} \\
\mathbf{E} \\
\mathbf{E} \\
\mathbf{D}\end{array}$ & $\begin{array}{c}\text { MA } \\
\text { X } \\
\text { LO } \\
\text { AD } \\
\text { (KN } \\
\text { ) }\end{array}$ & $\begin{array}{l}\text { FAI } \\
\text { LS } \\
\text { AT }\end{array}$ & $\begin{array}{c}\text { Tensil } \\
\text { e } \\
\text { streng } \\
\text { th } \\
\mathbf{N}_{2} / \mathbf{m m}\end{array}$ \\
\hline 1 & 100 & 100 & 200 & 194 & 6 & 4 & 10 & 20 & 1400 & 3 & 0.1 & 0.3 & $\begin{array}{l}7 \\
5\end{array}$ & 49.2 & $\begin{array}{l}\text { WE } \\
\text { LD }\end{array}$ & 314 \\
\hline 2 & 100 & 100 & 200 & 187 & 13 & 5 & 15 & 25 & 1400 & 3 & 0.1 & 0.3 & $\begin{array}{l}7 \\
5\end{array}$ & 54 & $\begin{array}{l}\text { WE } \\
\text { LD }\end{array}$ & 343 \\
\hline
\end{tabular}


Study Of Mechanical Behavior Of Friction Welded Joint In A Brass Material And Its Statistical

\begin{tabular}{|c|c|c|c|c|c|c|c|c|c|c|c|c|c|c|c|c|}
\hline 3 & 100 & 100 & 200 & 180 & 20 & 6 & 20 & 30 & 1400 & 3 & 0.1 & 0.3 & $\begin{array}{l}7 \\
5\end{array}$ & 53.6 & $\begin{array}{l}\text { NE } \\
\text { CK }\end{array}$ & 347 \\
\hline 4 & 100 & 100 & 200 & 187 & 13 & 5 & 10 & 30 & 1500 & 3 & 0.1 & 0.3 & $\begin{array}{l}7 \\
5\end{array}$ & 55.6 & $\begin{array}{l}\text { NE } \\
\text { CK }\end{array}$ & 363 \\
\hline 5 & 100 & 100 & 200 & 187 & 13 & 6 & 15 & 20 & 1500 & 3 & 0.1 & 0.3 & $\begin{array}{l}7 \\
5\end{array}$ & 52.4 & $\begin{array}{l}\text { WE } \\
\text { LD }\end{array}$ & 345 \\
\hline 6 & 100 & 100 & 200 & 186 & 14 & 4 & 20 & 25 & 1500 & 3 & 0.1 & 0.3 & $\begin{array}{l}7 \\
5\end{array}$ & 44.4 & $\begin{array}{l}\text { WE } \\
\text { LD }\end{array}$ & 295 \\
\hline 7 & 100 & 100 & 200 & 183 & 17 & 6 & 10 & 25 & 1600 & 3 & 0.1 & 0.3 & $\begin{array}{l}7 \\
5\end{array}$ & 52.4 & $\begin{array}{l}\text { WE } \\
\text { LD }\end{array}$ & 346 \\
\hline 8 & 100 & 100 & 200 & 185 & 15 & 4 & 15 & 30 & 1600 & 3 & 0.1 & 0.3 & $\begin{array}{l}7 \\
5\end{array}$ & 56.0 & $\begin{array}{l}\text { WE } \\
\text { LD }\end{array}$ & 354 \\
\hline 9 & 100 & 100 & 200 & 183 & 17 & 5 & 20 & 20 & 1600 & 3 & 0.1 & 0.3 & $\begin{array}{l}7 \\
5\end{array}$ & 50.8 & $\begin{array}{l}\text { WE } \\
\text { LD }\end{array}$ & 344 \\
\hline
\end{tabular}

IV. Taguchi Analysis by Minitab software for Means of Tensile strength:-

Table 4.0: Response Table for Means of Tensile strength

\begin{tabular}{|c|c|c|c|c|}
\hline Level & Speed & Friction pressure & Friction time & Forging pressure \\
\hline 1 & 334.7 & 341.0 & 321.0 & 334.3 \\
\hline 2 & 334.3 & 347.3 & 350.0 & 328.0 \\
\hline 3 & 348.0 & 328.7 & 346.0 & 354.7 \\
\hline Delta & 13.7 & 18.7 & 29.0 & 26.7 \\
\hline Rank & 4 & 3 & 1 & 2 \\
\hline
\end{tabular}

The response tables show the average of each response characteristic (means) for each level of each factor. The tables include ranks based on Delta statistics, which compare the relative magnitude of effects. The Delta statistic is the highest minus the lowest average for each factor. Minitab assigns ranks based on Delta values; rank 1 to the highest Delta value, rank 2 to the second highest, and so on. Use the level averages in the response tables to determine which level of each factor provides the best result. In this Experiment the ranks indicate that Friction time has the greatest influence on the mean, forging pressure has the next greatest influence, Friction pressure has the next greatest influence, followed by Rotational speed.From this Experiment, our goal is to increase Tensile strength of friction welded joint for brass material, required factor levels that produce the highest mean. In Taguchi experiments, we always want to maximize the Mean. The level averages in the response tables show that means were maximized when the Friction time was 5 Sec, Forging pressure was 30 bar, friction pressure was 15 bar, and rotational speed was 1600 R.P.M.

Based on these results for maximized Tensile strength the factors should be set as:-

- Friction time $5 \mathrm{Sec}$

- Forging pressure- $30 \mathrm{bar}$

- Friction pressure- 15 bar

- Rotational Speed- 1600 R.P.M.

4.1 Main effects plot for Tensile Strength:-

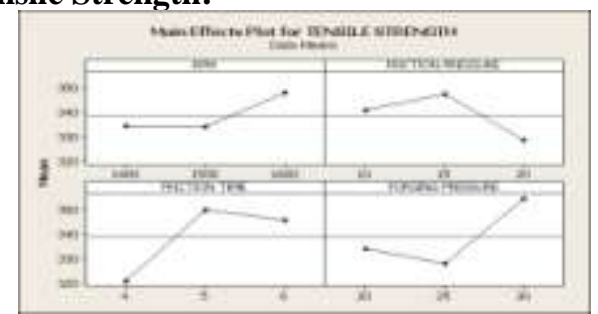

Graph 4.1: Main effect plot for Tensile Strength 
4.2 Interpreting the Main effects plot for Tensile Strength:-

Examining the main effects plots confirms these results. The main effects plot shows that, with the friction time $5 \mathrm{Sec}$, forging pressure $30 \mathrm{bar}$, friction pressure $15 \mathrm{bar}$ the tensile strength is maximized when the rotational speed is 1600 R.P.M.

\subsection{Interaction plot for Tensile strength:-}

\section{Interpreting the results:-}

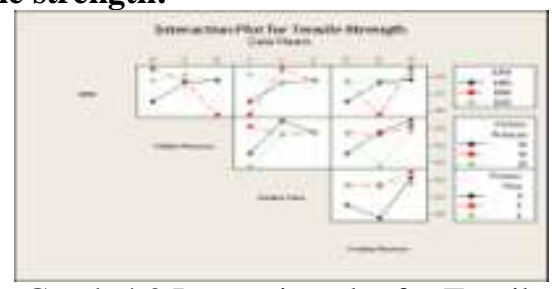

Graph 4.2 Interaction plot for Tensile strength

The above plot indicates an interaction between the all levels of all factors which are considered, for high tensile strength. 1500 r.p.m is better when the friction pressure is 10 to 15 bar, but the 1400 r.p.m is better when the friction pressure is 15 to 20 bar. 1500 r.p.m is better when the friction time is 4 to 5 sec. 1600 r.pm is better when the forging pressure is 20 to 25 bar and 1500 r.p.m is better when the forging pressure is 25 to 30 bar. 10bar friction pressure is better when the friction time is 4 to 5 sec. 10 bar friction pressure is better when the forging pressure is 25 to 30 bar. 6 sec friction time is better when the forging pressure is 20 to 25 bars but 5 sec friction time is better when the forging pressure is 25 to 30 bars.

\subsection{The regression equation for tensile strength:-}

TENSILE STRENGTH $=-4542+3.37$ speed -7.83 friction pressure +620 friction time +71.9 forging pressure -0.0493 speed $\mathrm{X}$ forging pressure -0.413 speed $\mathrm{X}$ friction time

Table 4.3: The regression Analysis Table for Tensile strength

\begin{tabular}{|c|c|l|l|l|l|c|c|}
\hline Runs & Speed & $\begin{array}{l}\text { Friction } \\
\text { pressure }\end{array}$ & $\begin{array}{l}\text { Friction } \\
\text { time }\end{array}$ & $\begin{array}{l}\text { Forging } \\
\text { pressure }\end{array}$ & $\begin{array}{l}\text { Tensile } \\
\text { strength }\end{array}$ & $\begin{array}{c}\text { Speed } \\
\mathbf{X} \\
\text { Forging } \\
\text { Pressure }\end{array}$ & $\begin{array}{c}\text { Speed } \\
\mathbf{X} \\
\text { Forging } \\
\text { time }\end{array}$ \\
\hline 1 & 1400 & 10 & 4 & 20 & 314 & 28000 & 5600 \\
\hline 2 & 1400 & 15 & 5 & 25 & 343 & 35000 & 7000 \\
\hline 3 & 1400 & 20 & 6 & 30 & 347 & 42000 & 8400 \\
\hline 4 & 1500 & 10 & 5 & 30 & 363 & 45000 & 7500 \\
\hline 5 & 1500 & 15 & 6 & 20 & 345 & 30000 & 9000 \\
\hline 6 & 1500 & 20 & 4 & 25 & 295 & 37500 & 6000 \\
\hline 7 & 1600 & 10 & 6 & 25 & 346 & 40000 & 9600 \\
\hline 8 & 1600 & 15 & 4 & 30 & 354 & 48000 & 6400 \\
\hline 9 & 1600 & 20 & 5 & 20 & 344 & 32000 & 8000 \\
\hline
\end{tabular}

By Minitab soft ware the values of R-Square and adjusted $\mathrm{r}$-square for above table is

R-Square $\left(\mathbf{R}^{2}\right)=\mathbf{9 4 . 3 \%}$
R-Square (adjusted) $\left(\mathbf{R}^{2}\right.$ adjusted) $=77.2 \%$
P-value $=0.161$

Interpreting the results of Table 5.9:-

The $\mathrm{R}^{2}$ value indicates that the predictors explain $94.3 \%$ of the variance in Tensile strength. The Adjusted $\mathrm{R}^{2}$ is $\mathbf{7 7 . 2 \%}$ which accounts for the number of predictors in the model. Both values indicate that the model fits the data well. The value of $\mathrm{R}^{2}$ and adjusted $\mathrm{R}^{2}$ are $94.3 \%$ and $77.2 \%$ respectively which signifies that regression model provides an excellent explanation of the relationship between the independent variables (factors) and the response tensile strength. The associated $\mathrm{P}$ value 0.161 for the model which is in between $0-1$ indicates that the model is statistically significant. 
Study Of Mechanical Behavior Of Friction Welded Joint In A Brass Material And Its Statistical 4.5 The regression analysis chart for tensile strength by Minitab soft ware:-

Table 4.4: Analysis of Variance for tensile strength

\begin{tabular}{|c|c|c|}
\hline Predictor & coefficients & P-value \\
\hline Constant & -4542 & 0.086 \\
\hline Speed & 3.367 & 0.079 \\
\hline Friction Pressure & -7.833 & 0.069 \\
\hline Friction Time & 620.2 & 0.069 \\
\hline Forging Pressure & 71.90 & 0.171 \\
\hline Speed X forging pressure & 0.00050 & 0.168 \\
\hline Speed X Friction time & -0.04933 & 0.071 \\
\hline
\end{tabular}

\section{Interpreting the results of Table 4.4}

Each coefficient estimates the change in the mean response per unit increase in X (predictor) when all other predictors are held constant. In the output above, if the speed variable increases by 1 unit and the other variables stay the same, Tensile strength increases by about3.37units on average. If the Friction pressure variable increases by 1 unit and the other variables stay the same, Tensile strength decreases by about7.83 units, on average. If the Friction time variable increases by 1 unit and the other variables stay the same, Tensile strength increases by about 620 units, on average. If the Forging pressure variable increases by 1 unit and the other variables stay the same, Tensile strength increases by about 71.9 units, on average If the Speed $\mathrm{X}$ forging pressure variable increases by 1 unit and the other variables stay the same, Tensile strength increases by about 0.0005 units, on average If the Speed X Friction time variable increases by 1 unit and the other variables stay the same, tensile strength decreases by about 0.04933 units, on average If the p-value (P) of a coefficient is less than the chosen, such as $0-1$, the relationship between the predictor and the response is statistically significant.

In the above table P-Values for all predictors are in between $0-1$, so the relationship between the predictor and the response tensile strength is statistically significant.

\section{Correlation between Experimental and predicted tensile strength:-}

Table4.5: Correlation between Experimental and predicted tensile strength

\begin{tabular}{|c|c|c|c|c|}
\hline Runs & RPM & $\begin{array}{c}\text { Experimental } \\
\text { Tensile Strength }\end{array}$ & $\begin{array}{c}\text { Predicted Tensile } \\
\text { Strength }\end{array}$ & Residual \\
\hline 1 & 1400 & 314 & 315.833 & -1.8333 \\
\hline 2 & 1400 & 343 & 332.333 & 10.6667 \\
\hline 3 & 1400 & 347 & 348.833 & -1.8333 \\
\hline 4 & 1500 & 363 & 367.667 & -4.6667 \\
\hline 5 & 1500 & 345 & 349.667 & -4.6667 \\
\hline 6 & 1500 & 295 & 299.667 & -4.6667 \\
\hline 7 & 1600 & 346 & 343.667 & 2.3333 \\
\hline 8 & 1600 & 354 & 351.667 & 2.3333 \\
\hline 9 & 1600 & 344 & 341.667 & 2.3333 \\
\hline
\end{tabular}

By Minitab software the values Pearson correlation co efficient for the table 5.10 is Pearson correlation co efficient of Experimental and predicted tensile strength $=\mathbf{0 . 9 7 1}$ and $\mathrm{P}-$ Value $=\mathbf{0 . 0 0 0}$

\section{Interpreting the results:-}

The correlation coefficient obtained for Experimental Tensile strength and predicted tensile strength is 0.971, when the value of correlation is more than $\mathbf{0 . 5}$, the two set of values said to be in correlation. The Pearson correlation between experimental and predicted Tensile strength is $\mathbf{0 . 9 7 1}$ which indicates there is direct intermediate correlation between experimental values and predicted values. Therefore the experimental tensile strength and predicted tensile strength values are said to be in correlation. The difference between an Experimental value and its corresponding Predicted value is the residual. 
Study Of Mechanical Behavior Of Friction Welded Joint In A Brass Material And Its Statistical

\subsection{Taguchi Analysis for upset versus speed, friction pressure, friction time, forging pres sure by} Minitab software:-

Table 4.6: Response Table for Means of Upset

\begin{tabular}{|c|c|c|c|c|}
\hline Level & Speed & Friction pressure & Friction time & Forging pressure \\
\hline 1 & 13.00 & 12.00 & 11.67 & 12.00 \\
\hline 2 & 13.33 & 13.67 & 14.33 & 14.67 \\
\hline 3 & 16.33 & 17.00 & 16.67 & 16.00 \\
\hline Delta & 3.33 & 5.00 & 5.00 & 4.00 \\
\hline Rank & 4 & 2 & 1 & 3 \\
\hline
\end{tabular}

The response tables show the average of each response characteristic (means) for each level of each factor. The tables include ranks based on Delta statistics, which compare the relative magnitude of effects. The Delta statistic is the highest minus the lowest average for each factor. Minitab assigns ranks based on Delta values; rank 1 to the highest Delta value, rank 2 to the second highest, and so on. Use the level averages in the response tables to determine which level of each factor provides the best result. In this Experiment the ranks indicate that Friction time has the greatest influence on the mean, friction pressure has the next greatest influence, forging pressure has the next greatest influence, followed by Rotational speed. From this Experiment, our goal is to decrease the upset or loss of length of friction welded joint for brass material, required factor levels that produce the lowest mean. From Taguchi experiments, the level averages in the response tables show that means were maximized when the Friction time was $6 \mathrm{Sec}$, Friction pressure was 20 bar, forging pressure was 30 bar, and rotational speed was 1600 R.P.M. And the Upset was minimized or reduced when the Friction time was $4 \mathrm{Sec}$, Friction pressure was 10 bar, forging pressure was 20 bar, and rotational speed was 1400 R.P.M. Based on these results for Minimized upset should set the factors at: , Friction time 4 Sec, Friction pressure10 bar, Forging pressure 20 bar ,Rotational Speed 1400 R.P.M.

\subsection{Main effects plot for Upset:-}

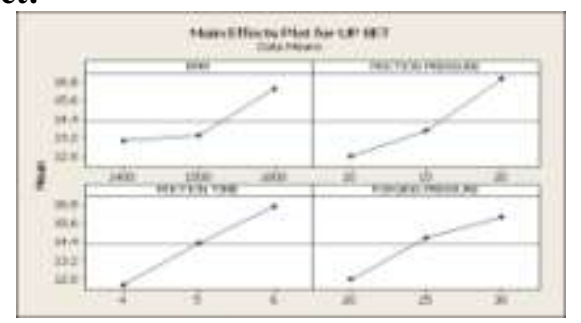

Graph 51: Main effect plot for Upset

Interpreting the Main effects plot for Tensile Strength:-

Examining the main effects plots confirms these results. The main effects plot shows that, with the friction time $6 \mathrm{Sec}$, forging pressure $30 \mathrm{bar}$, friction pressure 20 bar the upset is maximized when the rotational speed is 1600 R.P.M. And with the friction time 4 Sec, forging pressure 20 bar, friction pressure 10 bar the upset is minimized when the rotational speed is 1400 R.P.M.

Interaction plot for Upset:-

\section{Interpreting the results:}

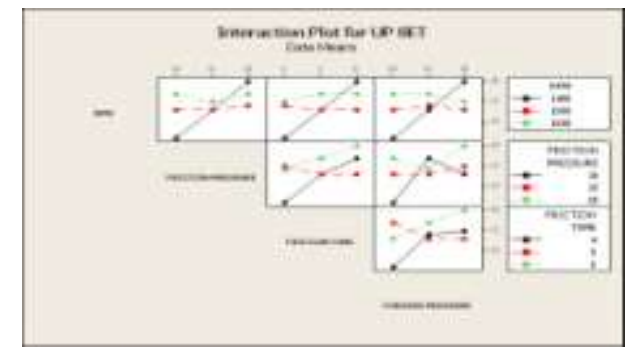

Graph 5.2 Interaction plot for Upset

1400 r.p.m is better when the friction pressure is 10 to 15 bars and at the same 1400 r.p.m has high upset when the pressure is 15 to 20 bars.

1400 r.p.m is better when the friction time is 4 to 5 sec. and at the same 1400 r.p.m has high Upset when the friction time is 5 to 6 sec. 1400 r.p.m is better when the forging pressure is 20 to 25 bars. And at the same 1400 r.p.m has high Upset when the forging pressure is 25 to 30 bars. 15 bar friction pressure is better when the friction time is 6 to $5 \mathrm{sec}$. but at 10 bar friction pressure has low upset when friction time is 4 to $5 \mathrm{sec} .15 \mathrm{bar}$ friction pressure is better when the forging pressure is 25 to 30 bar. But at 10 bar friction pressure has low upset 
Study Of Mechanical Behavior Of Friction Welded Joint In A Brass Material And Its Statistical when the forging pressure is 20 to 25 bars. 5 sec friction time is better when the forging pressure is 25 to 30 bar.bur at $4 \mathrm{sec}$ friction time has low upset when the forging pressure is 20 to 25 bar.

The regression equation for Upset:-

UPSET $=-40.8+0.0167$ speed +0.500 friction pressure +2.50 friction time +0.400 forging pressure

Table 5.3: The regression Analysis Table for Tensile strength

\begin{tabular}{|c|c|c|c|c|c|}
\hline Runs & $\begin{array}{c}\text { Speed } \\
\text { (R.P.M) }\end{array}$ & $\begin{array}{c}\text { Friction } \\
\text { pressure } \\
(\mathrm{bar})\end{array}$ & $\begin{array}{c}\text { Friction } \\
\text { time } \\
(\mathrm{sec})\end{array}$ & $\begin{array}{c}\text { Forging } \\
\text { pressure } \\
\text { (bar) }\end{array}$ & $\begin{array}{c}\text { Upset } \\
(\mathrm{mm})\end{array}$ \\
\hline 1 & 1400 & 10 & 4 & 20 & 6 \\
\hline 2 & 1400 & 15 & 5 & 25 & 13 \\
\hline 3 & 1400 & 20 & 6 & 30 & 20 \\
\hline 4 & 1500 & 10 & 5 & 30 & 13 \\
\hline 5 & 1500 & 15 & 6 & 20 & 13 \\
\hline 6 & 1500 & 20 & 4 & 25 & 14 \\
\hline 7 & 1600 & 10 & 6 & 25 & 17 \\
\hline 8 & 1600 & 15 & 4 & 30 & 15 \\
\hline 9 & 1600 & 20 & 5 & 20 & 17 \\
\hline
\end{tabular}

By Minitab soft ware the values of R-Square and adjusted r-square for above table is

R-Square $\left(\mathbf{R}^{2}\right)=\mathbf{9 5 . 2 \%}$

R-Square (adjusted) $\left(\mathbf{R}^{2}\right.$ adjusted) $=\mathbf{9 0 . 3 \%}$

P-value

$=\mathbf{0 . 0 0 7}$

Interpreting the results of Table 5.3:-

The $\mathrm{R}^{2}$ value indicates that the predictors explain $95.2 \%$ of the variance in Upset The Adjusted $\mathrm{R}^{2}$ is $90.3 \%$ which accounts for the number of predictors in the model. Both values indicate that the model fits the data well. The value of $R^{2}$ and adjusted $R^{2}$ are $95.2 \%$ and $90.3 \%$ respectively which signifies that regression model provides an excellent explanation of the relationship between the independent variables (factors) and the response Upset. The associated $\mathrm{P}$ value 0.007 for the model which is in between $0-1$ indicates that the model is statistically significant.

\subsection{The regression analysis chart for Upset by Minitab soft ware:-}

Table 5.4: Analysis of Variance for Upset

\begin{tabular}{|c|c|c|}
\hline Predictor & coefficients & P-value \\
\hline Constant & -40.08 & 0.008 \\
\hline Speed & 0.0167 & 0.028 \\
\hline Friction Pressure & 0.500 & 0.007 \\
\hline Friction Time & 2.500 & 0.007 \\
\hline Forging Pressure & 0.400 & 0.016 \\
\hline
\end{tabular}

Interpreting the results of Table 5.4:-

Each coefficient estimates the change in the mean response per unit increase in $\mathrm{X}$ (predictor) when all other predictors are held constant. In the output above, if the speed variable increases by 1 unit and the other variables stay the same, upset increases by about 0.0167 units on average. If the Friction pressure variable increases by 1 unit and the other variables stay the same, upset increases by about 0.500 units, on average. If the Friction time variable increases by 1 unit and the other variables stay the same, upset increases by about 2.500 units, on average. If the Forging pressure variable increases by 1 unit and the other variables stay the same, upset increases by about 0.400 units, on average.

Correlation between Experimental and predicted Upset:-

Table5.5: Correlation between Experimental and predicted Upset

\begin{tabular}{|c|c|c|c|c|}
\hline Runs & RPM & Experimental Upset & $\begin{array}{c}\text { Predicted } \\
\text { Upset }\end{array}$ & Residual \\
\hline 1 & 1400 & 6 & 5.55 & 0.44 \\
\hline 2 & 1400 & 13 & 12.55 & 0.44 \\
\hline
\end{tabular}


Study Of Mechanical Behavior Of Friction Welded Joint In A Brass Material And Its Statistical

\begin{tabular}{|c|c|c|c|c|}
\hline 3 & 1400 & 20 & 19.55 & 0.44 \\
\hline 4 & 1500 & 13 & 13.72 & -0.72 \\
\hline 5 & 1500 & 13 & 14.72 & -1.72 \\
\hline 6 & 1500 & 14 & 14.22 & -0.22 \\
\hline 7 & 1600 & 17 & 15.88 & 1.11 \\
\hline 8 & 1600 & 15 & 15.38 & -0.38 \\
\hline 9 & 1600 & 17 & 16.38 & 0.611 \\
\hline
\end{tabular}

By Minitab software the values Pearson correlation co efficient:-

Pearson correlation co efficient of Experimental and predicted Upset $=\mathbf{0 . 9 7 5}$

$\mathrm{P}-$ Value $=\mathbf{0 . 0 0 0}$

\section{Interpreting the results:-}

The correlation coefficient obtained for Experimental and predicted Upset is $\mathbf{0 . 9 7 5}$, when the value of correlation is more than $\mathbf{0 . 5}$, the two set of values said to be in correlation. The Pearson correlation between experimental and predicted is $\mathbf{0 . 9 7 5}$ which indicates there is direct intermediate correlation between experimental values and predicted values. Therefore the experimental upset and predicted Upset values are said to be in correlation. The difference between an Experimental value and its corresponding Predicted value is the residual.

\section{Conclusion}

Mechanical behavior of the friction welded joint for brass is studied by the Taguchi design of experiment and observed that the friction processed joint exhibited comparable strength with the base material and joint strength increased with increase in forging pressure at high and moderate levels of rotational speeds, and the optimal value of process variables for a higher tensile strength from the Taguchi design is 1600 R.P.M Speed, $5 \mathrm{sec}$ friction time, 15 bar friction pressure and 30 bar forging pressure It is observed that the Upset is decreased by all factors which are considered in friction welding process. It is found that the optimum values for less upset is 1400R.P.M Speed, $4 \mathrm{sec}$ friction time, 10 bar friction pressure and 20 bar forging pressure. A study of the regression analysis for both tensile and upset was done and the regression equation for both tensile and upset to predict the values of tensile and upset at any levels of process variables is studied and the correlation between experimental values and predicted values of both tensile and upset was established with a correlation co-efficient of 0.971 and 0.975 respectively which is more than 0.5 and hence Satisfactory as per the Taguchi standards. Studied the main affect, interaction and contour plots with the help of ANOVA for both tensile and upset and observed that at all levels of variables, There is an interaction between each other. And from the main affect plots it is observed that the level of factors that have more effect on the tensile strength and upset. From the Taguchi design of experiment it is observed that the factor that has more effect on the tensile strength is forging pressure, and on the upset, the effect of all the process variables is uniform. The microstructure at heat affected zone and weld zone was observed and it is found that the friction welded joint is excellent without any internal defects like blow holes, cracks, voids, impurities and grade size is fine towards the weld zone.

\section{References}

[1]. O. T. MIDLING, O. GRONG and M. CAMPING, in Proceedings of the 12th International Symposium On Metallurgy and Materials Science, Riso, edited by N. Hansen (Riso National Laboratory, Denmark, 1991) PP. 529-534.

[2]. H. KREYE and G. REINER, in Proceedings of the ASM Conference on Trends in Welding Research, Gatlinburg, TN, May 1986 edited by S. David and J. Vitek (ASM International Metals Park, 1986) PP. 728-731.

[3]. M. ARITOSHI, K. OKITA, T. ENDO, K. IKEUCHI and F. MATSUDA, Japan. Welding Society. 8 (1977) 50.

[4]. M. J. COLA, M.A.Sc thesis, Ohio State University, OH (1992).

[5]. M. J. COLA and W. A. BAESLACK, in Proceedings of the 3rd International. SAMPE Conference, Toronto Oct., 1992, edited by D. H. Froes, W. Wallace, R. A. Cull, and E. Struckholt, Vol. 3, PP 424-438.

[6]. Aeronautics for Europe Office for Official Publications of the European Communities, 2000.

[7]. ESSLINGER, J. Proceedings of the 10th World conference of titanium (Ed. G. LUTJERING) Wiley-VCH, WEINHEIM, Germany, 2003.

[8]. RODER O., Hem D., LUTJERING G. Proceedings of the 10th World conference of titanium (Ed. G. LUTJERING) Wiley-VCH, WEINHEIM, Germany, 2003.

[9]. $\quad$ BARREDA J.L., SANTAMARÍA F., AZPIROZ X., IRISARRI A.M. Y VARONA J.M. "Electron beam welded high thickness Ti6Al4V plates using filler metal of similar and different composition to the base plate". Vacuum 62 (2-3), 2001.PP 143-150

[10]. EIZAGUIRRE I., BARREDA J.L., AZPIROZ X., SANTAMARIA F. Y IRISARRI A.M. "Fracture toughness of the weldments of thick plates of two titanium alloys". Titanium 99, Proceedings of the 9th World Conference on Titanium: Saint Petersburg, (1999), PP. 1734-1740. 